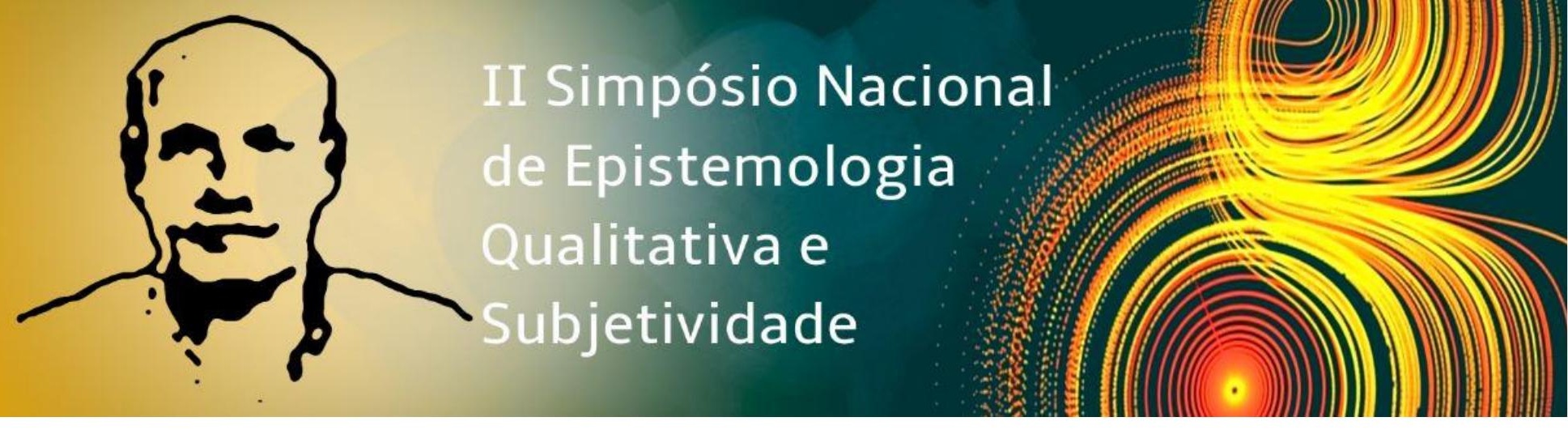

Eixo temático: Aprendizagem e dificuldades de aprendizagem na perspectiva da subjetividade

\title{
Contribuições da Teoria da Subjetividade para a superação das dificuldades de aprendizagem em ciências (física).
}

Sérgio Henrique de Oliveira Bezerra, UFPA, sergiohobezerra@ yahoo.com.br Andrela Garibaldi Loureiro Parente, UFPA, andrelagaribaldi40@gmail.com

\section{Resumo}

As dificuldades de aprendizagem apresentadas, sobretudo quanto aos conteúdos escolares de ciências, guardam vínculos com o desinteresse dos estudantes (POZO; CRESPO, 2009). A expressão desse desinteresse é um forte indicativo de elementos subjetivos presentes nas dificuldades de aprendizagem de física e em sua superação. O presente trabalho, ainda em andamento, tem como objetivo investigar a superação das dificuldades de aprendizagem, a partir de uma perspectiva centrada no sujeito que aprende, em contextos relacionados ao ensino de física na educação básica. Admitindo uma estreita relação entre o desinteresse dos estudantes e as dificuldades de aprendizagem, tomando como referencial a Teoria da Subjetividade (GONZÁLEZ REY; MITJÁNS MATÍNEZ, 2017), nos parece inadequado estabelecer uma relação de causa e efeito entre estes dois polos. Três movimentos complementares são necessários para produzir ideias e gerar inteligibilidade ao conjunto deste processo. 1. Apreciação de publicações veiculadas em periódicos da área de Educação em Ciências, buscando observar as situações tratadas nesses estudos, os problemas identificados e elementos associados à superação destes. 2. Assumindo que os eventos observados em ambientes escolares são complexos, pois tem no sujeito a centralidade de sua expressão, e que a aprendizagem de física apresenta dimensões específicas, avançaremos no processo construtivo-interpretativo investigando a dimensão subjetiva da dificuldade de aprendizagem em física. 3. Avançar no entendimento da superação das dificuldades de aprendizagem em física e problematizar sobre a relação entre desinteresse em aprender ciências e dificuldade de aprendizagem. Os resultados desta pesquisa, até o momento nos indicam que na Educação em 


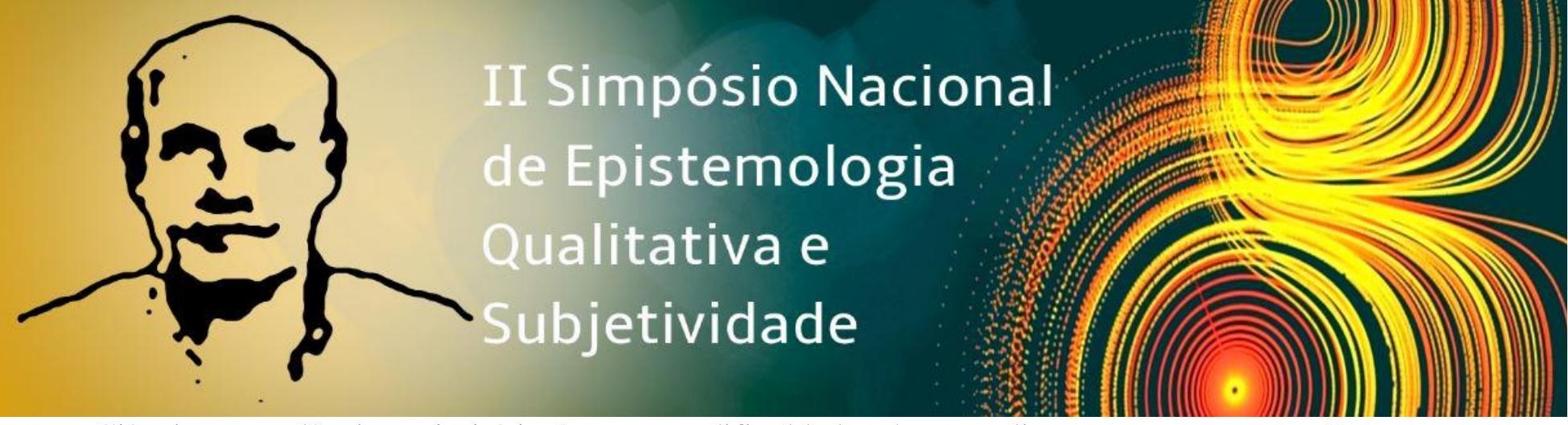

Ciências a tendência majoritária é tratar as dificuldades de aprendizagem, e sua superação, numa perspectiva eminentemente metodológica. Porém, identificamos abordagens (CACHAPUZ et al., 2011; POZO; CRESPO, 2009; ZABALA, 1998) que apresentam princípios convergentes com formas de aprendizagem compreensiva e criativa (MITJÁNS MARTÍNEZ; GONZÁLEZ REY, 2017). Embora seja possível observar suas potencialidades, é possível perceber que, o que em menor intensidade foi desenvolvido por essas abordagens foi o problema de como o sujeito aprende. Entendemos que a Teoria da Subjetividade pode contribuir para o aprender e ensinar física ao considerar o sujeito que aprende na dimensão simbólico-emocional e produtor de subjetividade individual e social. Assim nos cabe refletir sobre: Como se constitui a subjetividade de estudantes com dificuldades de aprendizagem em física?

Palavras chave: Dificuldades de aprendizagem. Ensino de física. Teoria da Subjetividade.

\section{Referências}

CACHAPUZ, A.; GIL PEREZ, D.; CARVALHO, A. M. P.; PRAIA, J.; VILCHES, A. (Org.). A necessária renovação do ensino de ciências. São Paulo: Cortez, 2011.

GONZÁLEZ REY, F. L.; MITJÁNS MARTÍNEZ, A. Subjetividade: teoria, epistemologia e método. Campinas: Alínea, 2017.

MITJÁNS MARTÍNEZ, A; GONZÁLEZ REY, F. Psicologia, educação e aprendizagem escolar: avançando na contribuição da leitura cultural-histórica. São Paulo: Cortez, 2017.

POZO, J. I.; CRESPO, M. A. G. A Aprendizagem e o ensino de ciências: do conhecimento cotidiano ao conhecimento científico. 5 ed. Porto Alegre: Artmed, 2009.

ZABALA, A. A prática educativa: como ensinar. Porto Alegre: Artmed, 1998. 